\title{
Diálogos entre Educação do Campo e Ensino de Ciências: possibilidades na formação de professoras/es de Ciências da Natureza
}

\section{Dialogues between Field Education and Sciences Teaching: possibilities in Nature Sciences teachers' education}

\author{
Marina Comerlatto da Rosa (mcomerlattodarosa@gmail.com) \\ Universidade Tecnológica Federal do Paraná (UTFPR)
}

\begin{abstract}
Adalberto Penha de Paula (adalbertoppenha@gmail.com)
Universidade Federal do Paraná (UFPR)
\end{abstract}

\begin{abstract}
Resumo: A Educação do Campo é uma conquista e uma produção coletiva, além de uma política pública construída a partir da luta de diferentes coletividades, com forte atuação dos movimentos sociais do campo. Objetiva-se refletir as possibilidades de articulação entre os princípios da Educação do Campo e um Ensino de Ciências emancipador na formação de professoras/es de Ciências da Natureza, evidenciando diálogos entre os conhecimentos científicos/escolares e os conhecimentos dos sujeitos envolvidos nos processos educativos realizados nas escolas e nos seus territórios. Utilizou-se do estudo bibliográfico e documental, descrição e análise reflexiva da saída de estudo em campo, realizada com alunas/os do curso de Licenciatura em Educação do Campo da Universidade Federal do Paraná (UFPR) - Setor Litoral, atividade de ensino que se deu no Parque Estadual de Vila Velha, no município de Ponta Grossa/PR. Após a análise da prática de ensino, observou-se que o diálogo de saberes/conhecimentos favorece a aprendizagem, ou seja, contribui significativamente para uma formação docente que respeita os saberes discentes e dão maior sentido ao conhecimento científico. Concluiuse que é preciso priorizar processos educativos condizentes com a realidade das/os alunas/os, além da necessidade de reconhecer e valorizar a cultura e conhecimentos dos sujeitos.
\end{abstract}

Palavras-chave: Educação do Campo; Formação de Professoras/es; Saída de Estudo em Campo.

\begin{abstract}
Field education is a collective achievement and production, as well as a public policy that was built from the struggle of different collectives, with strong action of the field social movements. Our aim is to reflect upon the possibilities of articulation between the field education principles and an emancipatory science teaching in the education of nature sciences teachers, evidencing the dialogue between scientific/school knowledge and the empirical knowledge of the individuals involved in the education processes developed in schools and their territories. This is a bibliographic and documental study, with the description and reflexive analysis of the field study outing carried out with the students from the Field Education Teaching Course at the Federal University of Paraná (UFPR) - Coast Sector, a teaching activity that occurred at the State Park of Vila Velha
\end{abstract}


in the municipality of Ponta Grossa/PR. When analyzing the teaching practice, we could observe that the dialogue between different types of knowledge favors learning, that is, it contributed significantly to the education of professionals that respect students' knowledge and make more sense of the scientific knowledge. Our results led to the conclusion that it is necessary to prioritize education processes consistent with the students' reality, and also to acknowledge and value the individuals' culture and knowledge.

Keywords: Field education; Teachers' education; Field study outing.

\section{INTRODUÇÃO}

Com a ascensão dos movimentos, organizações populares e sociais no Brasil, principalmente após a década de 1980, diferentes grupos se articularam para lutas que culminassem em conquistas defendidas coletivamente. Este contexto é o que caracteriza o processo de constituição da Educação do Campo (EdoC), que na década de 2000 conquistou o espaço das políticas públicas e também se inseriu, de forma mais efetiva, em diferentes segmentos da sociedade. Neste cenário, a EdoC apresenta singularidades, possibilidades e desafios frente as suas contribuições na formação dos reconhecidos povos do campo, águas e florestas, isto é, agricultoras/es familiar, camponesas/es, assentadas/os, acampadas/os, pescadoras/es artesanais, ilhéus, ribeirinhas/os, atingidas/os por barragens, indígenas, quilombolas e todas/os aquelas/es que se identificam como kevista, insionale Sclentla sujeitos que vivem no/do campo, águas e florestas.

O texto problematiza o projeto da Educação do Campo no Brasil, o Ensino de Ciências e a formação de professoras/es, mais especificamente, na área das Ciências da Natureza. Objetiva refletir as possibilidades de articulação entre os princípios da EdoC e um o Ensino de Ciências emancipador na formação de professoras/es de Ciências da Natureza. Busca-se demonstrar diálogos entre os conhecimentos científicos/escolares e os conhecimentos dos sujeitos envolvidos nos processos educativos realizados nas escolas e nos seus territórios, ou seja, conhecimentos populares, ancestrais e tradicionais.

Evidencia-se a importância do trabalho docente no processo de ensino e aprendizagem, pois é preciso um ato de pensar que considere "[...] o respeito ao senso comum no processo de sua necessária superação, quanto o respeito e o estímulo à capacidade criadora do educando. [...] o compromisso do educador com a consciência 
crítica do educando, cuja 'promoção' da ingenuidade não se faz automaticamente" (FREIRE, 1996, p. 29).

As reflexões realizadas são balizadas no estudo bibliográfico e documental (SEVERINO, 2007) e na descrição e análise reflexiva de uma saída de estudo em campo, realizada com uma turma da Licenciatura em Educação do Campo do Setor Litoral da Universidade Federal do Paraná (UFPR). Justifica-se este trabalho, por apresentar uma discussão necessária para o avanço na formação de professoras/es em Ciências da Natureza para atuar no contexto do campo, das águas e florestas, valoriza-se o uso de metodologias de ensino e aprendizagem que respeitem o conhecimento prévio das/os discentes, além de possibilitar outras formas de relação entre a dimensão abstrata e a dimensão concreta no ato de produção e apropriação do conhecimento científico.

Logo, este texto, além desta Introdução, organiza as discussões a partir dos seguintes tópicos: Educação do Campo no ensino superior: um projeto em construção; Ensino de Ciências a partir das saídas de campo no diálogo com o ensino de botânica; Trajetória metodológica da saída de campo. E por fim, as Considerações Finais que apontam as importantes contribuições da Educação do Campo na formação de docentes no ensino superior, a necessidade de um o Ensino de Ciências que contribua na apropriação de um conhecimento emancipador e o quanto é significativa o uso de metodologias de ensino que oportunize o contato com o concreto, para garantir novas relações entre sujeito e objetivo do conhecimento.

\section{EDUCAÇÃO DO CAMPO NO ENSINO SUPERIOR: UM PROJETO EM CONSTRUÇÃOO}

A Educação do Campo é a materialidade de um intenso processo de lutas pautadas pelos diferentes sujeitos do campo, das águas e das florestas, ou seja, populações que têm suas formas específicas de trabalho, modo de vida, de manifestar a sua cultura, produzindo e resistindo a partir dos seus territórios, identificados como,

[...] agricultores familiares, os extrativistas, os pescadores artesanais, os ribeirinhos, os assentados e acampados da reforma agrária, os trabalhadores assalariados rurais, os quilombolas, os caiçaras, os povos da floresta, os caboclos e outros que produzem suas condições materiais de existência a partir do trabalho no meio rural (BRASIL, 2010, p.1). 
Como toda conquista por direitos, a EdoC é marcada por processos de ocupação de um lugar que sempre foi negado aos sujeitos, neste caso, o acesso a uma educação de qualidade, não só a educação básica, mas também, ao ensino superior. No entanto, a conquistas de uma educação que atenda às suas demandas, enquanto sujeitos coletivos, ainda é um processo contínuo de construção. Visto que muitas das políticas educacionais voltadas às populações do campo, águas e florestas não atendem as suas especificidades, mas sim aos interesses de determinados grupos hegemônicos na sociedade brasileira, como foi o proposta do ruralismo pedagógico (BEZERRA NETO, 2016).

No entanto, o Movimento Nacional de Educação do Campo (CALDART, 2008, 2012; MUNARIM, 2008, 2011), vem se consolidado ao longo da história, a partir de singelas e grandes conquista, desde as esferas municipais a federal, o que reflete no avanço na elaboração e na efetivação das políticas de educação a estes sujeitos. É neste sentido que destacamos duas ações fundamentais, que se deram a partir do governo, mas com intensa pressão e participação dos movimentos e das organizações sociais e populares vinculadas ao campo, águas e florestas para garantia do acesso destas populações ao ensino superior.

Primeiramente, tem-se o Programa Nacional de Educação na Reforma Agrária (Pronera), gestado em 1997 no I Encontro Nacional das Educadoras e Educadores da ReformasAgrária, porém criado eme 1998, ne Ministério do Desenvolvimento Agrário, programa que oportunizou e ainda está vigente, mesmo que numa conjuntura desfavorável, acesso a formação superior em diferentes cursos e diversas instituições em todo país.

A outra ação voltada ao ensino superior é mais recente e tem como ponto de partida, o Decreto $\mathrm{n}^{\mathrm{o}} 7352 / 2010$, que instituiu a Política Nacional de Educação do Campo (PRONACAMPO), que atua em linhas específicas para efetivação desta política específica: I - Gestão e Práticas Pedagógicas (Programa Nacional do Livro Didático PNLD Campo; Programa Nacional Biblioteca da Escola - PNBE Temático; Mais Educação Campo); II - Formação Inicial e Continuada de Professores (Formação Inicial e Continuada de Professores, Escola da Terra); III - Educação de Jovens e Adultos e Educação Profissional (EJA Saberes da Terra, Programa Nacional de Acesso ao Ensino Técnico e Emprego) e IV - Infraestrutura Física e Tecnológica (Construção de Escolas, 
Inclusão Digital, PDDE Campo - Programa Dinheiro Direto na Escola, PDDE Água e Esgoto Sanitário - Programa Dinheiro Direto na Escola, Luz para Todos na Escola, Transporte Escolar).

E assim, a partir da linha II - Formação Inicial e Continuada de Professores, se elabora o Programa de Apoio à Formação Superior em Licenciatura em Educação do Campo (Procampo), o qual possibilita a criação dos cursos de Licenciatura em Educação do Campo, agora vinculados ao Ministério da Educação, com cursos em todo território brasileiro conforme Figura 1.

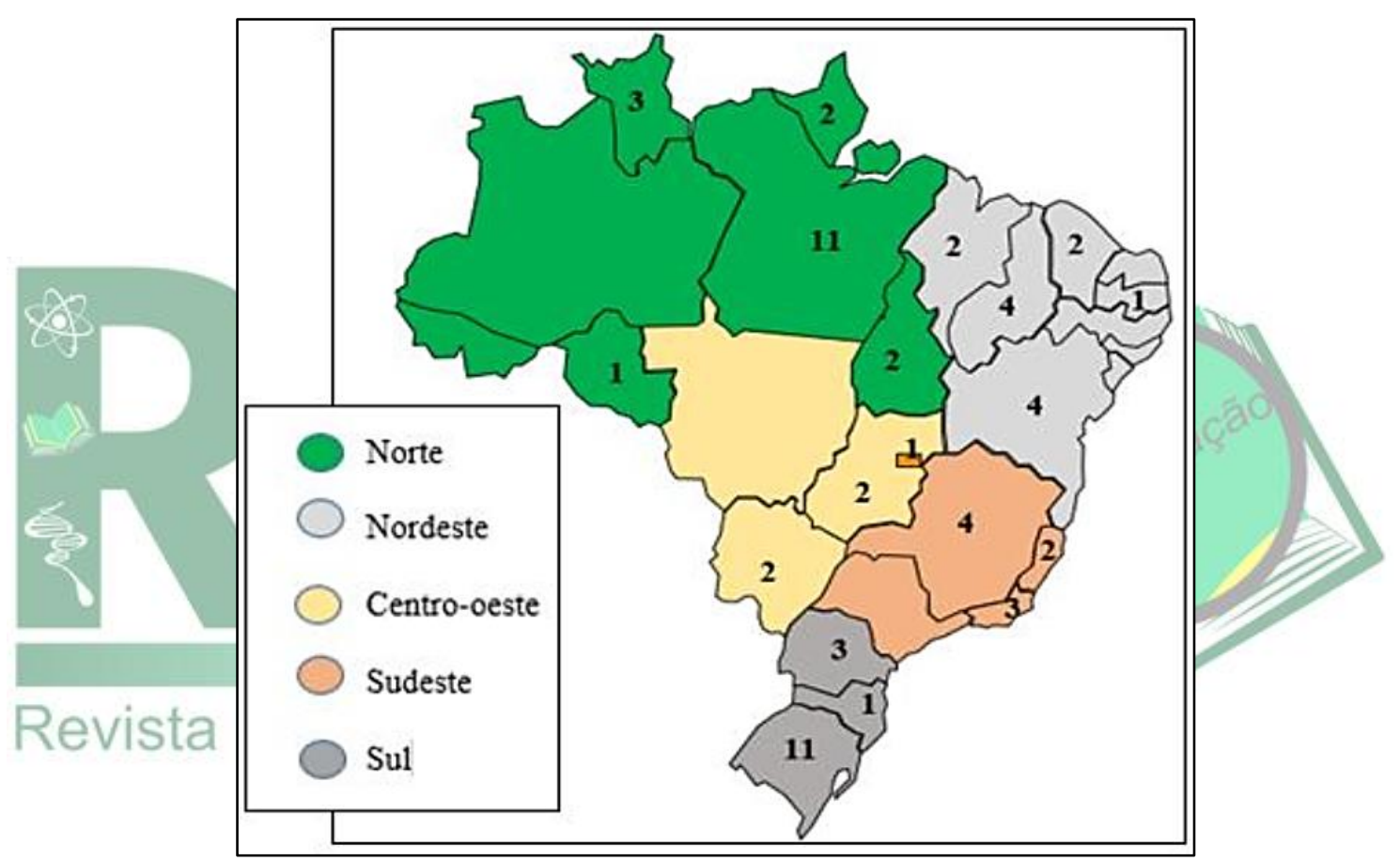

FIGURA 1 - Territorialização e quantitativo das Licenciaturas em Educação do Campo no Brasil Fonte: Scariot et al (2020)

Este contexto de territorialização das Licenciaturas em Educação do Campo reafirma-se que, de maneira geral, o curso tem como demanda central, suprir a falta de docentes para atuar nestas realidades, além de ofertar uma formação que atenda a demanda por educadoras e educadores que conhecem a realidade do campo, das águas e das florestas, assim estas licenciaturas "[...] objetivam formar e habilitar profissionais para atuação nos anos finais do Ensino Fundamental e Ensino Médio, por área de conhecimento e também para a gestão de processos educativos escolares e processos educativos comunitários." (MOLINA; HAGE, 2016, p. 806). 


\section{LICENCIATURA EM EDUCAÇÃO DO CAMPO NA UNIVERSIDADE FEDERAL DO PARANÁ - SETOR LITORAL}

Diante deste cenário de expansão das Licenciaturas em Educação do Campo no Brasil, mediante as políticas governamentais, que na UFPR, no Setor Litoral, a partir do Edital n²/2012 da Secretaria de Educação Continuada, Alfabetização, Diversidade e Inclusão (SECADI/MEC), as educadoras/es, deste Setor, em parceria com uma diversidade de sujeitos do litoral do Paraná, que vivem e trabalham no campo, nas águas e nas florestas pleitearam e posteriormente foram contemplados com a criação do curso de Licenciatura em Educação do Campo, na área de conhecimento das Ciências da Natureza, conhecido como Lecampo.

Porém, entre a elaboração, envio e aprovação do projeto pelo MEC e início das aulas foram dois anos de intensos diálogos para efetivação do curso somente em 2014, com a prerrogativa de contratação de quinze docentes efetivos, três técnicos em educação e um total de 360 vagas a serem ofertadas, conforme normativas do Edital n²/2012. Destaca-se que este curso, que outrora, iniciou como curso especial dentro da estrutura universitária, com o tempo conseguiu sua institucionalização tornando-se curso regular, como os demais ofertados pela UFPR.

Comozos demais cursos no Braisil, atecampo é ofertada no regime de alternância dos tempos educativos, com etapas específicas com o: a) Tempo Universidade (TU): momento de aulas com os docentes, interação com os demais discentes da turma, atividades a partir da universidade, acesso a laboratórios de ciências e informática, a biblioteca, enfim toda estrutura universitária e b) Tempo Comunidade (TC): momento de contanto com a realidade das comunidades de origem dos discentes, de trabalho a partir das demandas das escolas, realização de estudos a serem apresentados em uma próxima etapa do TU, buscando estabelecer relações entre este dos tempos educativos.

Esta organização pedagógica do curso é o que garante acesso aos estudantes, que antes de serem estudantes universitários já atuavam nas suas comunidades, viviam e trabalhavam sem ter condições de frequentar e deixar os seus territórios para terem aulas dentro do formato convencional das universidades no Brasil, pois muitos dos discentes 
são oriundos de lugares bem distantes e de difícil acesso, como comunidades quilombolas, indígenas, pescadoras/es artesanais, agricultoras/es familiares entre outros.

\begin{abstract}
A organização curricular em regime de alternância, composta por períodos de aprendizagem integrados entre Tempo Escola, nas Universidades públicas e Tempo Comunidade, que ocorre nas áreas rurais de origem destes educandos, objetiva não só evitar que o ingresso de jovens e adultos na educação superior reforce a alternativa de deixar de viver no campo, bem como objetiva promover a articulação entre educação e a realidade específica destas populações, possibilitando uma leitura crítica que, a partir dessa realidade, seja capaz de perceber as determinações sociais que assim a produzem, considerando a totalidade maior que a contém (MOLINA; ANTUNES-ROCHA, 2014, p. 230).
\end{abstract}

Ressalta-se na organização da Lecampo, a característica da Itinerância docente, isto é, o fato do curso ter turmas que têm aulas em outros territórios e não somente dentro da universidade, assim demandando formas de garantir o deslocamento das/os professoras/es até as comunidades, para que seja efetivado o Tempo Universidade, bem como, o acompanhamento do Tempo Comunidade.

No caso da Lecampo, o curso teve turmas no município da Lapa, no Assentamento Contestado com a parceria da Escola Latino Americana de Agroecologia (ELAA); no município de Cerro Azul, com aulas em um Centro Comunitário e em escolas municipais e estaduais com o apoio da prefeitura; no município de Adrianópolis, na comunidade quilombola de João Surá, com grande parte das aulas nas estruturas da escola estadual com apoio da prefeitura; além de turmas que têm como referência para o Tempo Universidade a estrutura do Setor Litoral da UFPR, localizada no município de Matinhos, contudo algumas aulas do curso são itinerantes, visto que os docentes e a turma se deslocam até as comunidades dos discentes para conhecer a realidade e o momento do Tempo Universidade.

As turmas da Lecampo têm como um dos princípios formativos a auto-organização, devido a esta estratégia educativa para consolidação das turmas, é proposto aos estudantes que definam nomes para as turmas. No sentido de que esta autodenominação possa contribuir na busca da unidade dos discentes, descoberta e aprendizado, enquanto identidade e trabalho coletivo.

Assim, desde 2014, o curso teve as seguintes turmas: Albert Einstein (2014-2018), com aulas no Assentamento Contestado no município da Lapa, Flor do Vale (2014-2018) com aulas no Centro Comunitário e escolas no município de Cerro Azul; turma Guará 
(2015-2019), com aulas nas dependências da UFPR - Setor Litoral em Matinhos, e em momentos específicos de aulas nos territórios dos estudantes como nos municípios de Antonina, Morretes e Guaraqueçaba e a turma Paulo Freire (2015-2019), com aulas na Comunidade Quilombola de João Surá no município Adrianópolis, estas já findaram sua trajetória formativas. Ainda em processo de formação com aulas na UFPR - Setor Litoral, tem-se as turmas Sementes Nativas (2017), Sepé Tiaraju (2018), Chico Mendes (2019) e turma 2020 (PAULA, 2019). Na figura 2 visualizam-se os territórios de onde as primeiras turmas da Lecampo tinham suas aulas.

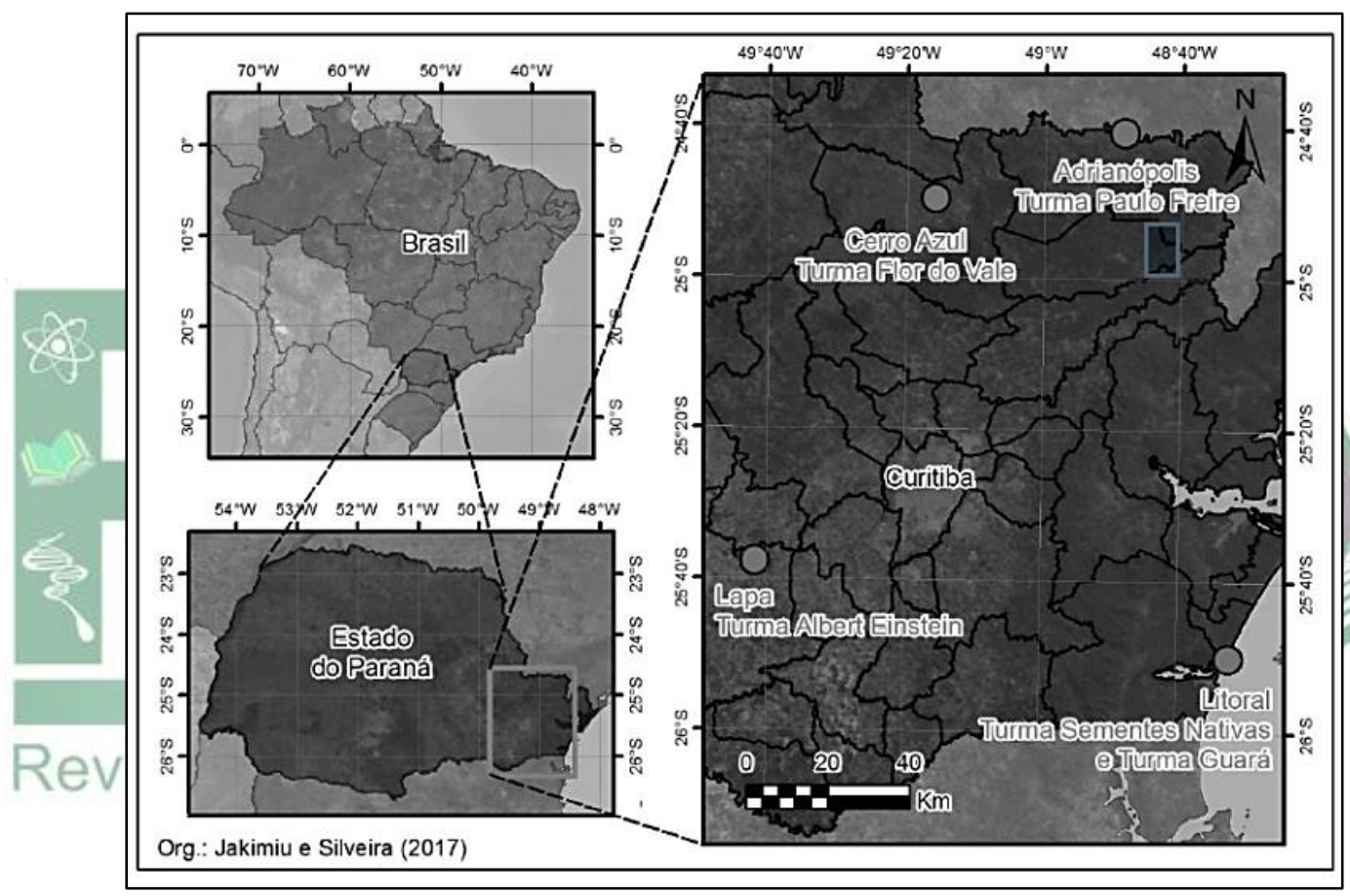

FIGURA 2 - Localização das aulas das primeiras turmas da Lecampo Fonte: Jakimiu (2018)

De acordo com PPC LECAMPO (2012), o curso tem como um dos pilares os pressupostos freirianos, na valorização do ser humano e da sua história, defendendo uma educação que vise a transformação social dos sujeitos, de forma que se realizem processo de reflexão crítica, reconhecimento das experiências individuais e coletivas, a partir da comunidade, fortalecendo assim, os processos de aprendizagem e de identidade dos discentes.

Assim, a formação de professoras/es licenciados em Educação do Campo na área de Ciências da Natureza, conforme o projeto pedagógico do curso, apresenta os seguintes objetivos que tem profundo diálogo com o ideário de Paulo Freire: 
[...] Promover uma pedagogia da alternância com um currículo vivo [...]; Proporcionar em conjunto com o educador uma escola formadora de sujeitos articulados a um projeto de emancipação humana; Possibilitar um espaço de valorização dos diversos saberes constituídos a partir da realidade do educando; Mobilizar e legitimar princípios e metodologias emancipatórias a partir da Educação do Campo [...]; Adensar a práxis socialmente envolvida nas formações dos professores do campo [...]; Implementar espaços coletivos de problematização das questões cotidianas acerca da exclusão histórica das pessoas do campo à educação e como consequência a exclusão a outros direitos e espaços no mundo do trabalho do campo e nele viver e produzir organicamente; Refletir e reagir coletivamente ante a histórica estrutura fundiária do latifúndio, da monocultura, do agronegócio, da expulsão da terra [...]; Valorizar os conhecimentos dos educandos, núcleos familiares e comunidades possuem estabelecendo um diálogo permanente com os saberes produzidos nas diferentes áreas do conhecimento; Considerar o trabalho como princípio educativo e vinculado a existência humana na relação com a natureza [...] (PPC LECAMPO, 2012, p. 16-17).

Buscando ser coerente com os objetivos formativos expressos no projeto pedagógico da Lecampo, cabe aos docentes do curso promover um trabalho com princípios e metodologias que respeite a história de vida de cada estudante, bem como, a história das suas comunidades, objetivando valorizar os conhecimentos prévios, isto é, da experiência de cada educanda/o os conhecimentos populares, ancestrais, tradicionais que são manifestados a partir da prática social na relação natureza, trabalho e sociedade. Pois, segundo Molina (2017, p. 590) “[...] essas Licenciaturas [...] são planejadas considerandose a luta de classes no campo brasileiro e colocando-se como parte e ao lado do polo do trabalho, assumindo e defendendo a educação como um direito e um bem público e social.

Produzir processos educativos no ensino superior na formação de docente para atuar em escolas, que atendam as populações do campo, das águas e das florestas, pressupõe trajetórias que visem outras possibilidades formativas, que tenham como princípio a “[...] imprescindível necessidade de superação da sociabilidade gerada pela sociedade capitalista [...]" (MOLINA, 2017, p. 592).

Neste horizonte, pressupõem-se escolas que assumam como objetivo fundante "[..] promover o diálogo entre os conteúdos científicos a serem ensinados em cada série/ciclo e os contextos socioterritoriais dos educandos, além da ampliação de sua compreensão dos conflitos e tensões presentes nesses territórios" (MOLINA, 2017, p. 604), produzindo uma organização do trabalho pedagógico, com processos de ensino e aprendizagem que contribuam em um projeto contra-hegemônico mais amplo e complexo, de subversão das 
relações sociais de violência, exploração e subordinação produzida pela lógica capitalista, visando a emancipação política e humanas dos sujeitos.

\section{ENSINO DE CIÊNCIAS A PARTIR DAS SAÍDAS DE CAMPO NO DIÁLOGO COM O ENSINO DE BOTÂNICA}

Considerando o projeto de educação pautado pelo Movimento Nacional de Educação do Campo, que se expressa tanto no ensino superior, através do Pronera e do Pronacampo, quanto na educação básica com as escolas localizadas nos territórios ocupados pelas populações do campo, das águas e florestas, problematiza-se o necessário Ensino de Ciências na formação de professoras/es de Ciências da Natureza, a partir de uma perspectiva histórica, crítica e de diálogo com os conhecimentos prévios dos sujeitos.

Almeja-se que os discentes universitários possam conjuntamente com o conhecimento científico, estabelecer novas experiências de apropriação do conhecimento na sua totalidade, de forma que o acúmulo de conhecimentos possa conduzi-los a vivências e ações transformadoras nas suas comunidades, visando o desvelamento da realidade, a socialização dos seus conhecimentos, a organização dos sujeitos e por fim, a ação coletiva no sentido de superar as formas de dominação e de opressão que as comunidades vivem no seu cotidiano, conforme os interesses dos grupos e setores historicamente dominantes na sociedade brasileira. Nesse sentido, expõe-se, a seguir, brevemente a história do Ensino de Ciências no Brasil e a importância de estratégias de ensino que estabeleçam relações significativas ao processo de aprendizagem no ensino superior.

Na década de 70 no Brasil, emergiram sugestões de aprimoramento do ensino de Ciências Naturais, no intuito de avançar aos novos processos pedagógicos e do conhecimento científico (BRASIL, 1998). De acordo com Krasilchik (2000), existiu a ideia de uma sequência fixa e básica em que a característica do método científico era a identificação de problemas, elaboração de hipóteses e verificação experimental dessas hipóteses, permitindo assim, que a/o aluno chegasse a uma conclusão e levantasse novas demandas. 
Sabe-se que o processo de ensino e aprendizagem passa por dificuldades, e não seria diferente com o Ensino de Ciências, é preciso novas metodologias que superem o modelo tradicional de ensino e que aproximem o conhecimento a realidade da/o aluna/o (COSTA; DUARTE; GAMA, 2019). O Ensino de Ciências preconiza que a/o aluna/o "aprenda conceitos fundamentais da área, compreenda a natureza e o processo de construção do conhecimento científico e seja capaz de analisar criticamente as implicações da Ciência e da Tecnologia na sociedade" (URSI et al, 2018, p. 08).

Dentre as áreas que constituem as Ciências da Natureza, a botânica é o foco deste escrito. Ao ensinar os conteúdos referentes à botânica, pretende-se que a/o aluna/o entenda os conceitos biológicos, baseando-os na construção de conhecimento e os associe às demais áreas da ciência, e não apenas na transmissão que promove apenas uma da abordagem memorística (URSI et al, 2018), levando as/os alunas/os ao desinteresse pelos conteúdos botânicos abordados (SILVA, 2008; STANSKI et al., 2016; ALVES, 2020). Ressalta-se a importância do ensino de botânica, pois é através dele, que também é possível conhecer e compreender o meio ambiente, e a partir disso, valorizá-lo (ALVES, 2020), levando assim, a conservação e cuidado com áreas naturais.

O desinteresse das/dos estudantes muito provavelmente ocorre pela falta de interação entre o ser humano (aluna/o) e as plantas, levando-os cada vez mais distantes da botânica. Dessa maneira, a saída de estude em campo apresenta um grande potencial para o processo de construção do conhecimento, no entanto, ela não é uma estratégia didático-metodológica recente.

Muitas outras denominações e/ou expressões são usadas para designar esta estratégia de ensino. Empregam-se expressões como atividade de campo, aula de campo, estudo do meio, aula passeio. O entendimento que se der ter, é que a saída de estudo em campo, termo que se utiliza neste artigo, tem que estar associada a uma finalidade pedagógica, exige um planejamento minucioso e não deve estar isolada dos conteúdos trabalhados em sala de aula, pois, do contrário, ela pode passar um entendimento errado, com uma conotação de apenas passeio, e não aula.

Pensar em diferentes estratégias de ensino que aperfeiçoem as aulas são essenciais para que ocorra uma articulação coesa entre os conteúdos ensinados, aprendidos, o contexto sócio-histórico vivido pelas/os alunas/os dentre outras dimensões do trabalho 
pedagógico. Ao utilizar estratégias diferenciadas de ensino, pode-se obter mais oportunidades para a construção do conhecimento, além de contribuir para que as/os alunas/os encontrem a melhor metodologia que a/o ajude a compreender o conteúdo estudado (VIVEIRO; DINIZ, 2009). Proporcionar as/aos alunas/os experiências pedagógicas distintas no seu processo de aprendizagem, faz com que a/o estudante tenha diferentes abordagens do conhecimento a ser assimilado e construído.

As saídas de estudo em campo apresentam-se como uma chance de trabalhar conhecimentos referentes a Ciências da Natureza num enfoque menos abstrato e fragmentado, possibilitando aproximar os conteúdos ensinados com o cotidiano das/os alunas/os, além de trazer diversos benefícios para o processo de ensino-aprendizagem:

Uma delas diz respeito aos ganhos em sociabilidade, particularmente em relação à autoestima, à capacidade de trabalho em equipe e ao relacionamento

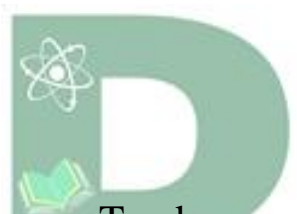
com colegas e professores. Uma segunda linha refere-se a associação entre aspectos afetivos e cognitivos. A terceira linha estaria relacionada à afetividade, com desenvolvimento de valores e atitudes favoráveis à conservação ambiental (FERNANDES, 2007, p. 28).

Tendo em mente a educação enquanto prática social, que oportuniza processos de sociabilidade e construção de relacionamentos entre a sociedade e a natureza, o ensino de Ciências da Natureza pode extrapolar a dicotomia teoria e prática, articulando o conhecimento científico com os saberes dos alunos.

\section{Revista Insianare Scientia}

[...] cabe repensarmos nossas metodologias de ensino, visando a estratégias de ensino-aprendizagem que levem em conta a dinâmica da construção do conhecimento pelo estudante. Torna-se imprescindível não considerar o aluno como tábula rasa, conhecer suas ideias prévias e entender as razões para sua resistência a mudanças em suas concepções cotidianas (LOPES, 1999, p. 228).

A/o aluna/o não deve ser visto como um receptáculo de conhecimentos, ela/ele ultrapassa uma visão escolar de decodificador/a de conteúdos aprendidos em sala de aula. Os processos de ensino-aprendizagem devem oportunizar a interpretação e a compreensão em relação ao mundo, aperfeiçoando as ideias e intervindo na realidade que se vive.

O ensino dos conteúdos relacionados com a ciência da natureza amplia “o repertório conceitual e cultural dos estudantes, auxiliando na análise crítica de situações reais e na tomada de decisões mais consciente, formando cidadãos mais reflexivos e capazes de 
modificar sua realidade" (URSI et al, 2018, p. 08), dessa maneira, formando a/o alunas/os que valorizam os saberes provenientes da vida social que trazem consigo.

\section{TRAJETÓRIA METODOLÓGICA DA SAÍdA DE CAMPO}

Ao ministrar aulas em diferentes ecossistemas e habitats específicos de diferentes seres vivos, tem-se um contato concreto com esse conhecimento, possibilitando uma melhor compreensão do ambiente natural (MARANDINO; SELLES; FERREIRA, 2009). Para isso, realizou-se uma saída de estudo em campo no Parque Estadual de Vila Velha (PEVV), uma unidade de conservação (UC), que está localizada no Segundo Planalto Paranaense, região dos Campos Gerais, no município de Ponta Grossa - Paraná. Possui 3.122,11 hectares com diversos atrativos dentre os quais se destacam os Arenitos, as Furnas e a Lagoa Dourada (SEMA/IAP, 2004).

Os arenitos lembram figuras como: índio, noiva, garrafa, bota e a famosa taça. As Furnas são crateras areníticas circulares de grande diâmetro e paredes verticais de até 100 metros de profundidade. A Lagoa Dourada é um importante local para a reprodução de peixes (TAKEDA, 2001). A UC foi criada pelo Decreto n. ${ }^{\circ} 1.292$ de 12 de outubro de 1953, com a finalidade de preservar as formações areníticas de grande valor cênico e parcelas representativas dos campos nativos do Paraná.

Os solos que predominam nesta região são sedimentares antigos, formados pela decomposição de arenitos e folhelhos, tendo como consequência, uma cobertura vegetal predominante de gramíneas (campos limpos), com capões de mato e matas ciliares que acompanham os cursos de água. As áreas com vegetação nativa remanescente são em sua maioria superfícies aluviais, capões de mato e matas de galerias (SEMA/IAP, 2004).

Para a concretização da saída de estudo em campo, realizou-se uma visita prévia à UC onde, em campo, estabeleceu-se pontos referenciais vinculados ao conteúdo botânico, levando em consideração uma boa visualização por todas/os as/os estudantes do material vegetal a ser estudado e o enfoque evolutivo. Em seguida, prosseguiu-se com a alocação visual, sendo seguida de demarcação em planilha própria e posteriormente, referenciada com registro fotográfico.

Após a análise e estabelecimento dos pontos referenciais, elaborou-se o roteiro de estudo em campo com o auxílio de bibliografia especializada e registros fotográficos. 
Selecionou-se as seguintes famílias: Arecaceae, Bromeliaceae, Cycadaceae, Polypodiaceae, Selaginellaceae, Dicksoniaceae, Araucariaceae, Anacardiaceae, Dennstaedtiaceae, Clethraceae, Euphorbiacea, Poaceae, Passifloraceae, Arecaceae. As espécies escolhidas para serem observadas, de modo geral, eram conhecidas pelos estudantes, tais como jerivá, bromélia, samambaia, musgo, xaxim, pinheiro do Paraná, aroeiras, capim gordura entre outras.

A segunda etapa foi relacionar a teoria com a prática em campo, ou seja, a contextualização do assunto, levando em consideração o ambiente natural e $\mathrm{o}$ conhecimento das/os alunas/os, visto que uma característica da turma é o vínculo orgânico com a natureza, pois são sujeitos que vivem e trabalham em contextos rurais, isto é, na sua grande maioria, são agricultoras/es familiares camponesas/es. A partir da vivência destes sujeitos foi possível uma maior interação em relação ao conhecimento científico, pois muitas/os alunas/os têm conhecimento profundo das plantas medicinais, trabalham com hortas, com o extrativismo de pequena escala, experiência de trabalho nas florestas das suas comunidades. Ressalta-se que a trilha foi realizada de maneira diferente do habitual, conforme Figura 3, a qual demonstra que o caminho percorrido foi a partir da trilha do bosque, onde encontra-se a maior variedade de plantas.

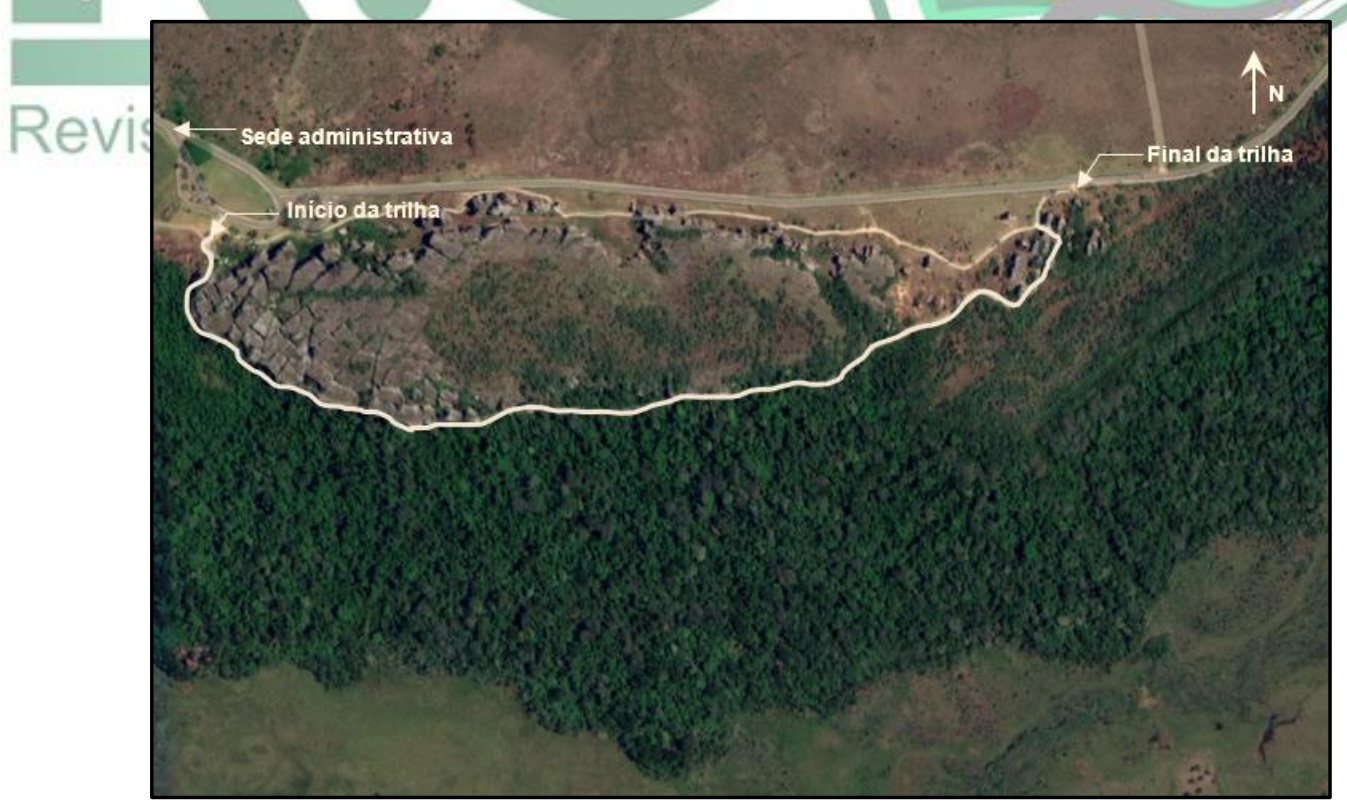

FIGURA 3 - Vista aérea da trilha do Parque Estadual de Vila Velha, Ponta Grossa-PR. Fonte: adaptado de Google Earth, 2020.

Destaca-se nesta saída de estudo em campo, o envolvimento das/os alunas/os em relação ao interesse em saber mais profundamente sobre determinada espécie, que alguns 
estudantes já conheciam das suas comunidades. Pode-se afirmar que essa atividade pedagógica estabeleceu um momento de exercício da curiosidade epistemológica.

\begin{abstract}
A construção ou a produção do conhecimento do objeto implica o exercício da curiosidade epistemológica, sua capacidade crítica de tomar distancia do objeto, de observá-lo, de delimitá-lo, de cindi-lo, de "cercar" o objeto ou fazer aproximações metódicas, sua capacidade de comparar, de perguntar (FREIRE, 1996, p. 85).
\end{abstract}

Salienta-se que a realização dessa atividade foi permeada de desafios, desde o processo de seleção de espécies a serem estudadas em sala de aula até a garantia das condições materiais para ida até o local da saída de estudo em campo, ou seja, transporte e também, alimentação.

A saída de estudo em campo foi realizada com uma turma do curso de Licenciatura em Educação do Campo - Ciências da Natureza, da UFPR, no Setor Litoral, onde grande parte das/os alunas/os têm atuação junto aos movimentos e organização sociais e populares do campo, das águas e das florestas. No seu início, teve matriculadas/os alunas/os de vários estados: Rondônia, Pará, Paraná, Mato Grosso e São Paulo e Santa Catarina conforme Figura 4, demostrando sua heterogeneidade.

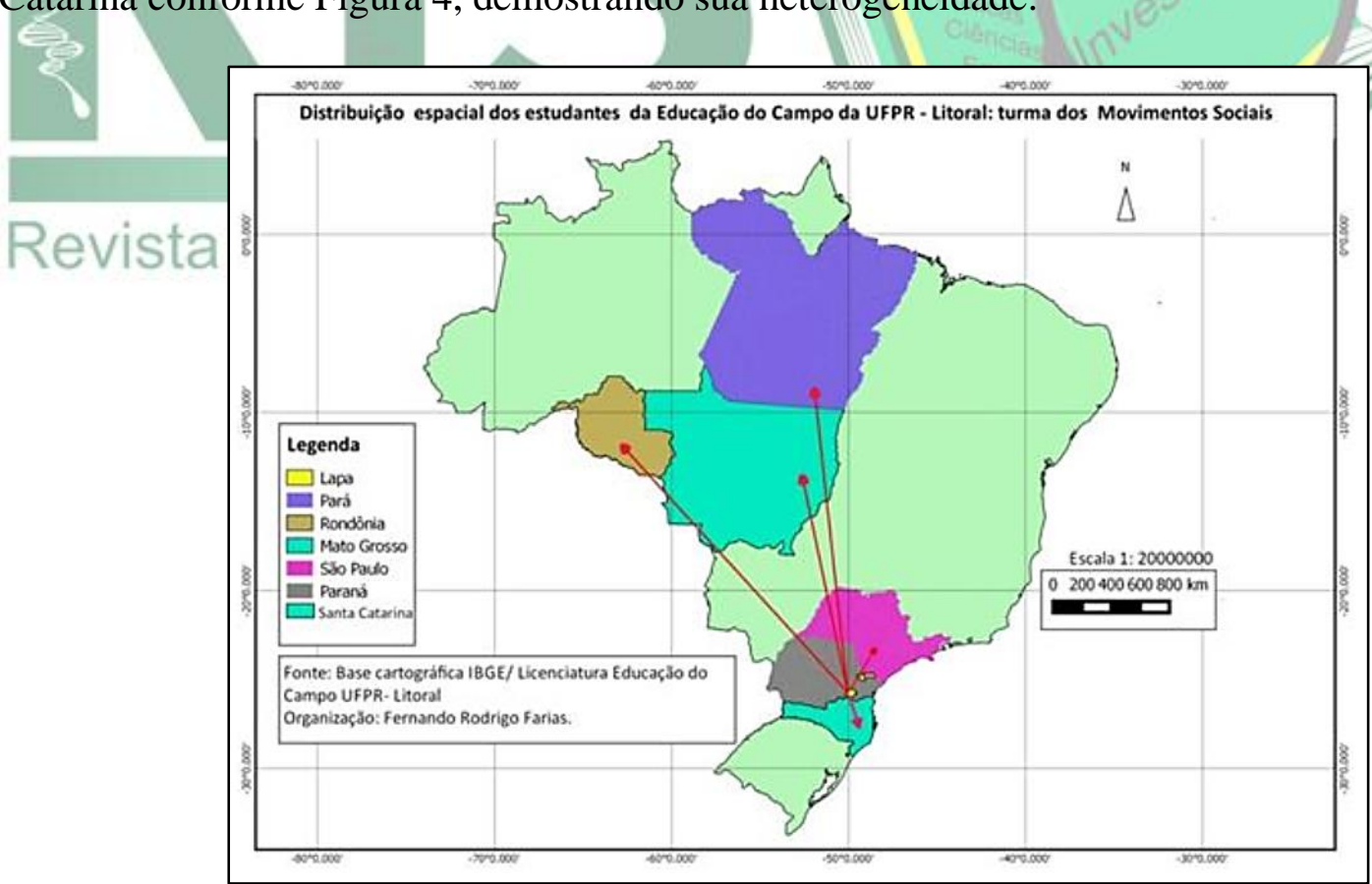

FIGURA 4 - Territórios de origem dos estudantes da turma Albert Einstein da Lecampo Fonte: Martins (2019).

Outra característica relevante a ser destacada é o fato de que a formação da turma se deu a partir da parceria entre UFPR e a Escola Latino Americana de Agroecologia 
(ELAA), situada no Assentamento Contestado no município da Lapa-PR, escola que tem uma proposta educativa vinculada às demandas dos movimentos sociais do campo, principalmente, os articulados na Via Campesina. Também, destaca-se que, na proposta pedagógica da ELAA, os tempos educativos têm particularidades na sua organização, de forma a proporcionar diferentes vivências para além do momento das aulas.

Enfatiza-se que a articulação entre universidade, isto é, o Setor Litoral da UFPR e os movimentos sociais do campo que é representada nesta parceria com a ELAA e os estudantes da turma Albert Einstein é muito significativa no processo de consolidação da Educação do Campo no ensino superior. Visto que é uma das formas de manter viva a coerência dos pilares fundantes da Educação do Campo na Lecampo, considerando que a sua constituição se dá a partir da materialidade da vida dos sujeitos. Enquanto sujeitos individuais com uma identidade coletiva, produzida no engajamento com os movimentos e organização sociais e populares do campo, das águas e das florestas.

\section{CONSIDERAÇÕES FINAIS}

Ao refletir as possibilidades de articulação entre os princípios da Educação do Campo e um Ensino de Ciências emancipador na formação de professoras/es de Ciências da Natureza, evidenciando diálogos entre os conhecimentos científicos/escolares e os conhecimentos dos sujeitos envolvidos nos processos edueativos realizados nas escolas e nos seús territórios, entende-se que cènsinot de botânica não deve ser baseado em métodos que privilegiam a reprodução e memorização do conteúdo, e desconsideram o saber prévio da/o aluna/o, pois dessa forma o conhecimento é apenas teórico e desestimulante a/ao estudante.

A diversidade dos sujeitos das turmas do curso de Licenciatura em Educação do Campo - Ciências da Natureza é um elemento central da proposta de uma formação de professoras/es que conhecem a realidade e podem realizar um trabalho educativo nas escolas mais coerente com as demandas da comunidade. O processo formativo realizado juntamente com os docentes, prevê um itinerário que estabeleça fecundos diálogos com os territórios e, consequentemente, com os conhecimentos populares, ancestrais, tradicionais que os discentes trazem consigo ao ingressarem na Lecampo. 
Também, foi possível evidenciar que o uso da saída de estudo em campo, como estratégia metodológica para o Ensino de Ciências, mais especificamente, o ensino de botânica, favoreceu o contato com o concreto, de modo que, juntamente com a dimensão abstrata do conhecimento problematizado sobre o tema da aula, possibilitou maiores conexões em relação a apropriação do conhecimento na sua totalidade. Além de que, os estudantes, puderam identificar diferentes espécies que também estão presentes nas suas comunidades, situação que contribuiu para ampliação do conhecimento de cada discente em relação a determinada espécie.

\section{REFERÊNCIAS}

ALVES, Robson Marinho. Ensino de botânica na Educação Superior: investigação e análise dos obstáculos no processo ensino-aprendizagem em instituições públicas do Amapá, Brasil. 2020. 69 f. Dissertação (Mestrado em Ciências Biológicas - Botânica Tropical) - Universidade Federal Rural da Amazônia/Museu Paraense Emílio Goeldi, Belém, 2020.

BEZERRA NETO, Luiz. Educação rural no Brasil: do ruralismo pedagógico ao movimento por uma educação do campo. Uberlândia: Navegando Publicações, 2016.

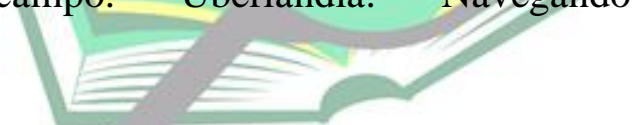

BRASIL, Ministériocda Educação. Secretaria de Ensino Fundamental. Parâmetros Curriculares Nacionais. Brasília: MEC/SEF,1998.

BRASIL. Decreto 7352 de 04 de novembro de 2010. Disponível em: < http://portal.mec.gov.br/docman/marco-2012-pdf/10199-8-decreto-7352-de4-denovembro-de-2010/file >. Acesso em: 10 ago. 2020.

CALDART, Roseli Salete. Sobre Educação do Campo. In: SANTOS, Clarice Aparecida (Org.). Por uma Educação do Campo: campo - políticas públicas - educação. Brasília: Incra; MDA, 2008.

CALDART, Roseli Salete. Educação do Campo. In: CALDART, Roseli Salete; PEREIRA, Isabel Brasil; ALENTEJANO, Paulo; FRIGOTTO, Gaudêncio. (Org.). Dicionário da Educação do Campo. Rio de Janeiro: Escola Politécnica de Saúde Joaquim Venâncio; São Paulo: Expressão Popular, 2012 
COSTA, Emanuelle Almeida da; DUARTE, Rafaela Andressa Fonseca; GAMA, José Aparecido da Silva. A gamificação da botânica: uma estratégia para a cura da "cegueira botânica”. Revista Insignare Scientia, v. 2, n. 1, p. 79-99, set/dez., 2019.

FERNANDES, José Artur Barroso. Você vê essa adaptação? a aula de campo em Ciências entre o teórico e o empírico. 2007. 326 f. Tese (Doutorado em Educação) Faculdade de Educação, Universidade de São Paulo, São Paulo, 2007.

FREIRE, Paulo. Pedagogia da Autonomia: saberes necessários à prática educativa. São Paulo: Paz e Terra, 1996.

GOOGLE EARTH. Parque Estadual de Vila Velha Disponível em: < https://earth.google.com/web/search/Parque+Estadual+de+Vila+Velha+-+Ponta +Grossa,+Paran\%c3\%a1,+Brasil/@-25.25219355,-49.99968172,891.7755718a, 3890.0110906d,35y,0h,0t,0r/data=CigiJgokCUzTIr2Tb0hAEXESuMZabEhAGT2uL7i YgQJAIfy9xIixUgJA >. Acesso em: 30 jul. 2020.

JAKIMIU, Camila. A formação de educadores(as) do campo como ferramenta para o fortalecimento da r-existência camponesa: tecendo interpretaçốes da realidade com a turma Albert Einstein da Lecampo da UFPR - Setor Litoral. 2018. 200 f. Dissertação (Mestrado em Geografia) - Universidade Federal do Paraná, Curitiba, 2018.

KRASILCHIK, Myriam. Reformas e Realidade: o caso do ensino das Ciências. São Paulo em Perspectiva, y. 14, n. 1, p. 85-93, 2000.

LOPES, Glice Ribeiro Casimiro. Conhecimento escolar: ciência e cotidiano. Rio de Janeiro: UERJ, 1999.

MARANDINO, Martha; SELLES, Sandra Escovedo; FERREIRA, Marcia Serra. Ensino de Biologia: história e práticas em diferentes espaços educativos. São Paulo: Cortez, 2009.

MARTINS, Taise Costa Curta. Licenciatura em Educação do Campo: trajetória formativa da turma Albert Einsten. 2018. 69 f. Trabalho de Conclusão de Curso (Licenciatura em Educação do Campo - Ciências da Natureza) - Setor Litoral, Universidade Federal do Paraná, Matinhos, 2018.

MOLINA, Mônica Castagna; ANTUNES-ROCHA, Maria Isabel. Educação do Campo: história, práticas e desafios no âmbito das políticas de formação de educadores - reflexões sobre o Pronera e o Procampo. Revista Reflexão e Ação, Santa Cruz do Sul, v. 22, n. 2, p. 220-253, jul./dez., 2014. 
MOLINA, Mônica Castagna; HAGE, Salomão Mufarrej. Riscos e potencialidades da expansão das Licenciaturas em Educação do Campo. RBPAE, v. 32, n. 3, p. 805-828, 2016.

MOLINA, Mônica Castagna. Contribuições das Licenciaturas em Educação do Campo para as políticas de formação de educadores. Educ. Soc., v. 38, n. 140, p. 587-609, 2017.

MUNARIM, Antônio. Movimento Nacional de Educação do Campo: uma trajetória em construção; In: Reunião Anual da ANPEd, 31., 2008, GT 3 - Movimentos Sociais e Educação, Caxambu. Anais... Caxambu: ANPEd, 2008. Disponível em: < http://31 reuniao.anped.org.br/1 trabalho/GT03-4244--Int.pdf >. Acesso em: 03 ago. 2020.

MUNARIM, Antônio. Educação do Campo e políticas públicas: controvérsias teóricas e políticas. In: MUNARIM, Antônio et al. (Orgs.). Educação do Campo: políticas públicas e práticas pedagógicas. Florianópolis: Insular, 2011. p. 21-38.

PAULA, Adalberto Penha de. Relações entre Educação do Campo e Território: significados da escola da/na ilha para uma comunidade tradicional de Guaraqueçaba no litoral do Paraná. 2019. 257 f. Tese (Doutorado em Educação) - Universidade Federal do Paraná, Curitiba, 2019.

PPC LECAMPO. Projeto Pedagógico do Curso de Licenciatura em Educação do Campo - Ciências da Natureza. Setor Litoral: Matinhos, 2012.

SCARIOT, Jaqueline Rodrigues da Silva Sfredo; ALVES, Ana Claudia Tasinaffo; LEÃO, Marcelo Franco; LOPES, Thiago Beirigo. Panorama de Cursos de Licenciatura em Educação do Campo no Brasil. Revista Brasileira Educação do Campo, Tocantinópolis, v. 5, e5820, 2020.

SEMA/IAP. Plano de Manejo Parque Estadual de Vila Velha. Curitiba. 2004. Disponível em: < http://www.iap.pr.gov.br/modules/conteudo/conteudo.php? conteudo=1255 >. Acesso em: 01 ago. 2020.

SEVERINO Antônio Joaquim. Metodologia do trabalho científico. 23. ed. São Paulo: Cortez, 2007.

SILVA, Patrícia Gomes Pinheiro da. O ensino da botânica no nível fundamental: um enfoque nos procedimentos. 2008. 148 f. Tese (Doutorado em Educação em Ciências) Universidade Estadual Paulista, Faculdade de Ciências, Bauru, 2008.

STANSKI, Carin; LUZ, Cynthia Fernandes Pinto; RODRIGUES, Adriana Ribeiro Ferreira; NOGUEIRA, Melissa Koch Fernandes de Souza. Ensino de Botânica no Ensino 
Fundamental: estudando o pólen por meio de multimodos. Hoehnea, v. 43, n. 1, p. 1926, 2016.

TAKEDA, Inês Janete Matozzo; FARAGO, Paulo Vitor. Vegetação do Parque Estadual de Vila Velha. Curitiba: Serzegraf, 2001.

URSI, Suzana; BARBOSA, Pércia Paiva; SANO, Paulo Takeo; BERCHEZ, Flávio Augusto de Souza. Ensino de Botânica: conhecimento e encantamento na educação científica. Estudos Avançados, v. 32, n. 94, p. 07-24, 2018.

VIVEIRO, Alessandra Aparecida; DINIZ, Renato Eugênio da Silva. Atividades de campo no ensino das ciências e na educação ambiental: refletindo sobre as potencialidades desta estratégia na prática escolar. Ciência em Tela, v. 2. n. 1, p. 1-12, 2009.
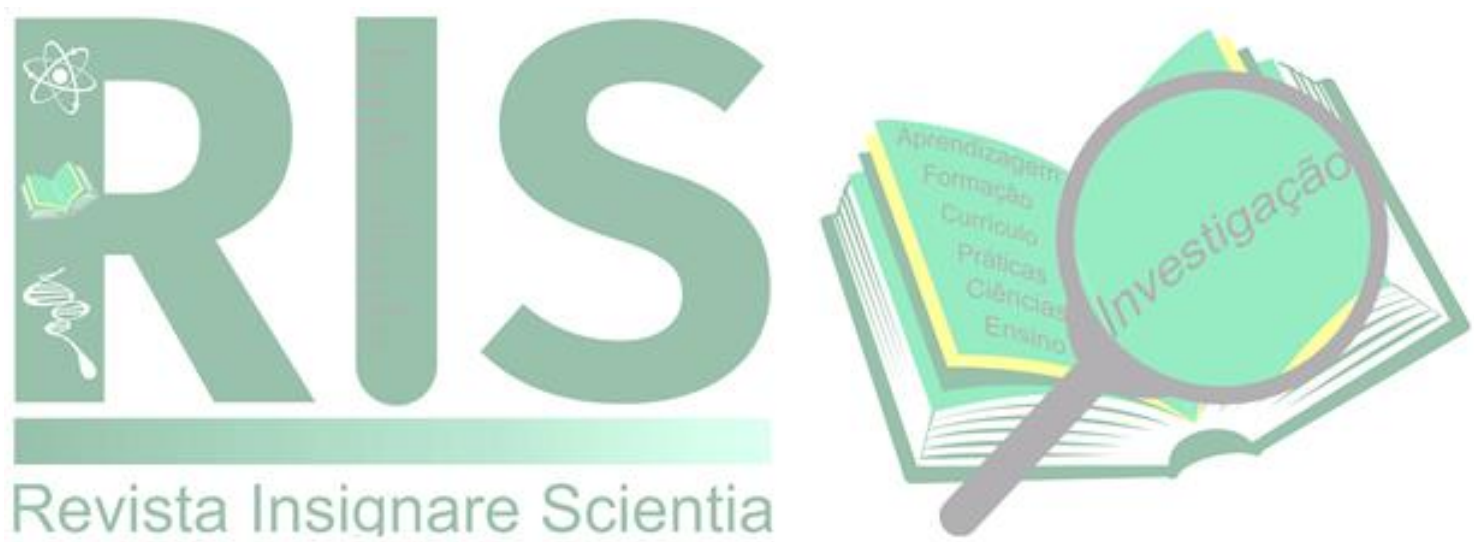